\title{
Migrant farmworkers' perceptions of pesticide risk exposure in Adams County, Pennsylvania: A cultural risk assessment
}

\author{
Micaela Edelson, ${ }^{a}$ Salma Monani, ${ }^{a *}$ and Rutherford V. Platt ${ }^{a}$ \\ Gettysburg College
}

Submitted July 10, 2017 / Revised September 14, October 27, and November 10, 2017 / Accepted

November 10, 2017 / Published online March 9, 2018

Citation: Edelson, M., Monani, S., \& Platt, R. V. (2018). Migrant farmworkers' perceptions of pesticide risk exposure in Adams County, Pennsylvania: A cultural risk assessment. Journal of Agriculture, Food Systems, and Community Development, 8(1), 71-96. https://doi.org/10.5304/jafscd.2018.081.005

Copyright (C) 2018 by the Authors. Published by the Lyson Center for Civic Agriculture and Food Systems. Open access under CC BY license.

\begin{abstract}
Agricultural exceptionalism, a system in which regular labor laws and standards do not apply to farm labor, makes migrant farmworkers particularly vulnerable populations-economically, socially, and in terms of environmental health. To address inequities inherent in migrant farmworker marginalization, studies advocate for actively engaging the migrant farmworker population in the conversation surrounding these issues. We conducted 40 semistructured interviews with migrant farmworkers in Adams County, Pennsylvania, to understand pesticide risk exposure perceptions and practices. We employed the Health Belief Model as our cultural risk assessment frame, using it in combination with technical risk assessment, which uses government calculations (from the Environmental Protection Agency) to quantify pesticide risk exposure. We used mixed methods analyses (quantitative and qualitative) to compare and understand farmworker
\end{abstract}

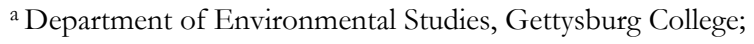
Box 2455; 300 North Washington Street; Gettysburg, PA 17325 USA.

* Corresponding author: Salma Monani, smonani@gettysburg.edu demographics, perceived risk, perceived control, and risk behavior. Results show that demographics —e.g., age, education, visa status—are important factors in risk perception. They also confirm observations present in many earlier studies. While trainings and educational materials are valuable to help build awareness of risk, a systemic lack of control over their circumstances make it hard for migrant farmworkers to engage in safe behavior. Results also highlight the limitations of technical risk assessment. Such calculations, however, rarely account for risk perceptions and experiences of farmworkers themselves. Acknowledging the voices of migrant farmworkers is an essential first step in rebalancing inequities of power in our food

\section{Funding Disclosure}

Micaela Edelson was funded by a U.S. Environmental Protection Agency, Greater Research Opportunities (GRO) Fellowship. This publication was developed under Assistance Agreement No. 91777801-0 awarded by the U.S. Environmental Protection Agency to Micaela Edelson. It has not been formally reviewed by EPA. The views expressed in this document are solely those of Micaela Edelson, Salma Monani, and Rutherford Platt and do not necessarily reflect those of the Agency. EPA does not endorse any products or commercial services mentioned in this publication. 
systems, and cultural risk assessment can help frame recommendations that target different stakeholders across the pesticide regulatory spectrum to ensure migrant farmworker needs and safety.

\section{Keywords}

Migrant Farmworkers; Pesticides; Cultural and Technical Risk Assessments; Health Belief Model; Pennsylvania

\section{Introduction}

In 1962, Rachel Carson's Silent Spring and Murray Bookchin's Our Synthetic Environment exposed scientific research that alerted the American public to the ecological and health impacts of pesticides. At the same time, Cesar Chavez and Dolores Huerta's establishment of the United Farm Workers Union (UFW) alerted the nation to migrant farmworker conditions. While their work has influenced policies such as the establishment of the Environmental Protection Agency (1970), the Occupational Health and Safety Act (1970), and the Worker Protection Standard (originally enacted in 1992 with several revisions that have modified the act, including the most recent revision in 2017), various studies note that the general characteristic that defines the farming sector is one of agricultural exceptionalism. Legacies of systemic racism, indentured servitude, and entrepreneurial exploitations persist in public policy and on-the-ground practice. Such policies and practices inhibit farmworkers' rights to regular standards and laws of labor protection, including those of occupational health (Rodman, Barry, Clayton, Frattaroli, Neff, \& Rutkow, 2016; Weiler, Levkoe, \& Young, 2016). For example, state-level policies often undermine federal-level labor protections, specifically with regards to minimum wage, overtime protections, and meal and rest periods (Rodman et al., 2016). Farm work is notoriously demanding, and through much of the nation's history, farmworkers have consisted of groups disenfranchised along lines of race, ethnicity, and citizenship status (Gray, 2013;

\footnotetext{
${ }^{1} \mathrm{H}-2 \mathrm{~A}$ is a federal work-visa program that partners U.S. employers with foreign workers to fill temporary or seasonal agricultural jobs. It is explicitly aimed to satisfy needs of employers who are unable to find willing, qualified, and/or
}

Holmes, 2013; Southern Poverty Law Center, 2013). The National Center for Farmworker Health estimates that there may be more than three million migrant farmworkers in the U.S. (2012), most of whom come from Mexico and Central America (Southern Poverty Law Center, 2013). Some come on temporary $\mathrm{H}-2 \mathrm{~A}$ visas as part of the $\mathrm{H}-2$ guest worker program, ${ }^{1}$ but the bureaucracy associated with this program makes it uninviting and difficult. Thus, many migrant farmworkers remain undocumented in the federal system (Gray, 2013; Holmes, 2013; Rodman et al., 2016).

Working long hours in fields, orchards, barns, and slaughterhouses, migrant farmworkers are at the frontlines of pesticide risk exposure. At a fundamental level, their safety is dependent on the defined limits on pesticide use instituted by federal and state governments. Specifically, the U.S. Environmental Protection Agency (EPA) employs numerical equations for oral, dermal, and inhalation exposure to calculate the risk associated with pesticide exposure and to designate proper application use and restrictions. Such calculations compose a technical risk assessment. However, scholars have argued that technical risk assessments fail to comprehensively assess risk, as risk is subjective and socially constructed. When communities do not have a say in decision-making, both the risk assessments and the communities at risk can overestimate or underestimate the threat (Bickerstaff, 2004; Cox, 2012; Finucane \& Holup, 2005; National Research Council, 1996; Renn, 1992). In contrast to technical risk assessment, cultural risk assessment considers how and why risk is understood and perceived differently by certain populations and individuals. For example, Bickerstaff (2004) found that political and economic marginalization of a group tended to escalate personal concerns about environmental risks (specifically air pollution in her case study) as well as feelings of helplessness. This was caused by, and contributes to, a lack of trust that government and regulatory agencies will act justly. In essence, the voices of those at risk are

available U.S. workers for the temporary work, and is predicated on workers returning to their home countries when the job needs are satisfied. 
important. As Patricia Allen writes in the introduction to this journal's special issue (2016), Labor in the food system, from farm to table, "where workers are not consulted, knowledge and policy cannot take into account the circumstances, motivations, and aspirations of those at the point of production... This is dangerous for workers and consumers alike" (p. 2). By capturing the voices of those at risk, cultural risk assessment can help address important safety considerations to protect marginalized farmworkers.

The primary objective of this study is to better understand the factors that influence the perception of pesticide risk held by migrant farmworkers. The study draws on previous pesticide studies that engage cultural risk assessments and provides two new dimensions to such research. First, this study puts technical risk assessment methods in direct dialogue with cultural risk assessment. Embracing both aspects of risk is important to align the interests of different stakeholders (e.g., farm owners, the government, and farmworkers) in order to identify and enforce pesticide exposure risk mitigation strategies. Second, this study focuses on Adams County, Pennsylvania, an important agricultural region in which many farmers are dependent on migrant labor; nevertheless, it is a region that has not been well studied. Indeed, despite the approximately 45,000 to 50,000 migrant and seasonal farmworkers in Pennsylvania, there is only one study examining occupation health and migrant farmworker perceptions (Cason, Snyder, \& Jensen, 2004). Our findings can illuminate and shape migrant farmworker safety concerns, risk communication, and pesticide exposure standards; thus, we also make recommendations for pesticide risk mitigation strategies.

\section{Pesticide Exposure and Risk. Assessment}

Pesticide exposure studies identify a wide range of pesticide-related illnesses from which migrant farmworkers suffer due to chronic, low exposure to pesticides, primarily absorbed dermally and secondarily inhaled or ingested (Arcury \& Quandt, 1998; Arcury, Quandt, Cravey, Elmore, \& Russell, 2001; Ciesielski, Loomis, Mims, \& Auer, 1994; Colt, Stallones, Cameron, Dosemeci, \& Zahm,
2001; Sakala, 1987; Wilk, 1986). Symptoms and illnesses from pesticide exposure include headaches, nausea, dermatitis, respiratory failures, musculoskeletal problems, cognitive effects, and cancer. In some cases, death can be an outcome.

Assessing the health effects of chronic, lowlevel exposure to pesticides is inherently complicated. Health effects from pesticide exposure can be easily mistaken for other occupational health symptoms that farmworkers may experience-for example, heat stress and reaction to plants (Arcury $\&$ Quandt, 1998). Furthermore, the transient nature of migrant farmworkers coupled with their often undocumented status makes longitudinal tracking of participants particularly difficult. For example, illnesses such as cancers can take years to appear following occupational pesticide exposure (Arcury $\&$ Quandt, 1998). Since direct measurement of pesticide exposure is time consuming and difficult, governmental and research organizations use risk assessment models instead.

\section{Technical Risk Assessment of Pesticide Exposure}

The U.S. Environmental Protection Agency (EPA) typically uses a technical risk assessment protocol to calculate the risk associated with pesticide exposure and to designate application use and restrictions. The agency employs the National Research Council's process for human health risk assessment: hazard identification, dose-response assessment, exposure assessment, and risk characterization (Pedersen, 1997). Furthermore, the EPA acknowledges three main routes that can lead to pesticide exposure: oral, inhalation, and dermal. The EPA has several calculations for determining exposure (Pederson, 1997; U.S. EPA, 1994, 2007; U.S. EPA, Office of Pesticide Programs, 2002; U.S. EPA, Office of Pesticide Programs, 2013; U.S. EPA, Office of Superfund Remediation and Technology Innovation, 2004). Models that best measure pesticide exposure for farmworkers consider factors such as contaminant residue, contact with the residue, frequency, time span, duration of exposure, and body weight to calculate an Average Daily Dose (ADD) for all three routes of exposure. The ADD can then be compared to the EPA's data on a particular pesticide's Oral 
Reference Dose (RfD) or Inhalation Risk Concentration (RfC), an estimate of a daily exposure to the human population that is likely to be without an appreciable risk of deleterious effects during a lifetime. RfD and RfC are experimentally determined, often by using test animals. A Hazard Quotient (HQ) is calculated to determine risk by dividing the $\mathrm{RfD}$ (or RfC) by the ADD. If the HQ is greater than one, an adverse health effect is expected (U.S. EPA, 2005; U.S. EPA, Office of Superfund Remediation and Technology Innovation, 2004).

Dermal exposure risk, calculated specifically for farmworkers, is an estimate of the dermal exposure via a transfer coefficient, a known variable for most crops and activity combinations (e.g., hand harvesting of peaches). The dermal exposure uses the same units as ADD ( $\mathrm{mg} / \mathrm{kg}$-day), so the same HQ equation applied to oral and inhalation exposure can be used to calculate the dermal exposure (U.S. EPA, Office of Pesticide Programs, 2013).

Overall, technical risk assessments provide generalizable calculations to inform worker safety legislation; however, they do have limitations. First, calculations do not consider the cumulative risk of oral, inhalation, and dermal exposure. That is, there are three separate HQs for each exposure type, but none that considers them together. Second, they do not consider the combination and/or interaction of different chemicals that one might be exposed to within the individual calculations of exposure.

Third, they do not consider an individual's perceptions or experiences of risk, which, as a number of studies indicate, is essential to effectively addresses risk (Bickerstaff, 2004; Cox, 2012; Finucane \& Holup, 2005; National Research Council, 1996; Renn, 1992). If people do not perceive themselves to be at risk, they might not take necessary mitigating action, thus endangering themselves and others. Conversely, if people perceive greater risk than what exists, this too can be problematic, as it results in unnecessary concern and resource misallocation. Thus, cultural risk assessment has been utilized in pesticide risk studies, as elaborated below, to resolve such limitations associated with technical risk calculations.

Cultural Risk Assessment of Pesticide Risk
Using the Health Belief Model (HBM) Cultural risk assessment examines how risk is understood and perceived by different populations and individuals (Bickerstaff, 2004). A common model for cultural risk assessment is the Health Belief Model (HBM), which seeks to assess how behavior is a function of a person's subjective appraisal of risk and recognizes that perceiving risk is the first step toward taking action for risk mitigation. The HBM posits that there are six variables that predict risk behavior: risk susceptibility, risk severity, benefits to action and barriers to action, self-efficacy, cues to action, and demographics (Hayden, 2013; Jones et al., 2015; Table 1).

Methodologically, studies informed by HBM use statistical analyses to understand the correlations between these variables. An extensive metaanalysis of HBM research conducted by Jones, Jensen, Scherr, Brown, Christ, and Weaver (2015) identified certain limitations of the HBM model. Most notably, the ordering of variables is currently undefined in the HBM. For example, it does not define whether relationships occur in parallel (are severity and susceptibility simultaneous?), in serial (does severity effect susceptibility?), or in tandem

\section{Table 1. HBM Variables that Predict Risk Behavior a}

\begin{tabular}{ll}
\hline HBM variables & Definition \\
\hline Risk susceptibility & The belief one is at risk \\
Risk severity & By how great the risk is \\
Benefits/Barriers to risk behavior & If a behavior will mitigate risks \\
Self-efficacy (or barriers to self-efficacy) & The belief one can(not) take action to mitigate risk \\
Cues to action & Knowledge provided by educational material or personal experience \\
Demographics & Age, ethnicity, socioeconomic status, etc. \\
\hline
\end{tabular}

a Risk behavior is defined as the likelihood that a person will engage in a risky or risk-mitigation behavior. 
(do severity and susceptibility occur together, even if they are ordered?).

These limitations notwithstanding, the HBM is still a useful conceptual starting point for understanding risk (Jones et al., 2015). The model has been applied frequently to understand pesticide risk behavior (Arcury, Quandt, \& Russell, 2002; Khan, 2010; Quandt et al., 2001; Snipes et al., 2009).

These studies often simplify the model to examine specific variable correlations of interest. For example, in their study focused on North Carolina farmworkers, Arcury et al. (2002) examined how susceptibility and severity contribute to understandings of perceived risk and how self-efficacy contributes to perceived control. They were also interested in how access to safety information correlated to perceived risk and control.

Many studies on pesticide risk use the HBM as a frame; others do not use this framework explicitly, but rather use pesticide risk components that overlap that of HBM. Whether qualitative or quantitative, these studies seek to understand participants' perceptions, including perceptions of risk control. For example, in their qualitative analysis of interviews with farmworkers in California's Salinas Valley, Cabrera and Leckie (2009) found that many farmworkers have higher levels of risk perception than the general public, but nonetheless engage in risky behaviors (e.g., wearing short sleeves or no shirt in the fields). Cabrera and Leckie suggest that such risky behavior may be because farmworkers do not believe they have control (i.e., self-efficacy) over reducing their exposure, even if they change their behavior. However, a qualitative analysis by Elmore and Arcury (2001) showed that farmworkers who have perceived control, such as the ability to wash their hands and shower immediately following work (again, a form of self-efficacy), do engage in mitigation behaviors. Using a multivariable ordinal logistic regression analysis, Levesque and Arif (2014) similarly suggest that perception of control can predict reduced pesticide exposure among seasonal and migrant farmworkers. Their findings are supported by studies such as Arcury et al. (2002), which cite the HBM as a frame. Arcury et al. (2002), Damalas and Hashemi (2010), and Snipes et al. (2009) also explore how demographic variables are correlated with risk behavior. Overall, the HBM, even when simplified to focus on a subset of variables, is a useful conceptual model for assessing pesticide risk.

\section{Research Design}

\section{Research Question and Conceptual Model}

As with previous studies, we wished to learn how perceived risk, perceived control, and demographics relate to pesticide risk behavior in order to facilitate the development of effective risk mitigation strategies. Thus, in this study we ask the following research question: how do four crucial aspects of cultural risk assessment - perceived risk, perceived control, demographics, and risk behavior — correlate to each other? In addressing this question, as with many previous studies (e.g., Arcury et al., 2002; Khan, 2010; Quandt, Arcury, \& Pell, 2001; Snipes et al., 2009), we engage the HBM as a conceptual frame and simplify it to illuminate broad understandings of risk and control perceptions, demographics, and risk behavior (Figure 1).

\section{Figure 1. Conceptual Model Based on Health Belief Model Variables Indicating the Relationships Explored in this Study} The demographic variables, which we understand as modifying factors for the three other categories, are listed in Table 2.

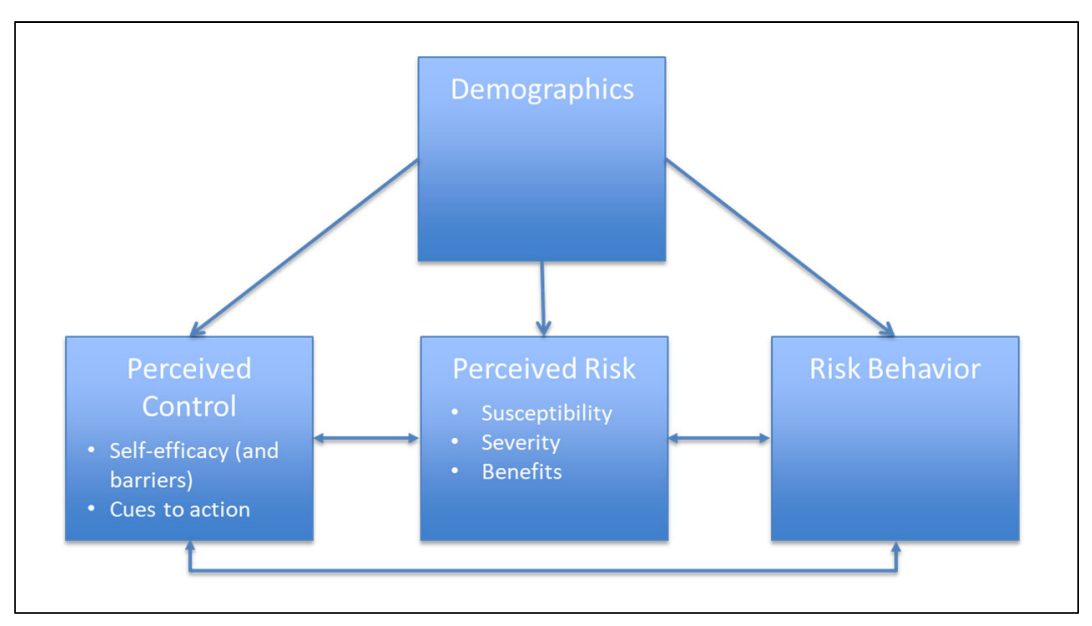


Our research was conducted with many of the principles of community-based research (CBR) in mind. We initiated the study based on the invitation of community partners who are well known and trusted within the migrant community, namely the Lincoln Intermediate Unit (LIU) Migrant Education Program in Pennsylvania (a program that assists farmworkers primarily through educational opportunities). Though the specific time constraints of the farmworkers meant we were unable to collaborate on survey design, our research was conducted with the explicit aim to share findings with our community partners and to respect and validate the knowledge of the farmworkers to help generate social change. These three principles of community collaboration-working on topics of concern initiated by the community, sharing knowledge with them, and validating stakeholder knowledge to instigate social change-are central to CBR (Gettysburg College, Center for Public Service, 2017).

\section{Survey Design}

To answer the research question, we designed a survey that maintains compatibility with previous pesticide risk studies that conducted statistical analyses centered around HBM variables. In designing our survey, we used Likert scale questions (similar to those use by Quandt et al., 2001, Arcury et al., 2002, and Cabrera and Leckie, 2009), and, because we were keen to understand the concerns of farmworkers in their own voices, we also included openended questions.

The survey was designed to be administered in 30 to 60 minutes and was tested in the field before it was deployed. This test resulted in a shortening of the original survey-for example, we removed a few perceived control questions we had originally taken from the Arcury et al. (2002) study in favor of keeping the openended questions. While our shortened survey instrument did not allow us to generate the perceived control indices that Arcury et al. (2002) developed, it was quicker and simpler to administer than the test survey. The resulting survey (Appendix A) included 12 perceived risk questions, 15 perceived control questions, 8 demographic questions, and 2 risk behavior questions. It also included 6 technical risk assessment questions, which we initially hoped to utilize to create estimates of actual exposure. The survey was available in both English and Spanish.

Our survey instrument is not exactly the same as those used in previous works, which could be construed as a limitation. However, given that many studies, such as Snipes et al. (2009), tailor their HBM frame to their specific research sites and concerns, we do not necessarily see this as a problem. Instead, as we discuss in the results, our survey still yielded many valuable insights that can be used in conjunction with previous studies. In addition, the qualitative information gained from the openended questions added important nuances to our statistical relationships.

\section{Data Collection}

LIU's Migrant Education Program helped facilitate contact with farmworkers at 13 housing sites in Adams County, Pennsylvania. We conducted 40 semistructured interviews with seasonal workers between September and October 2016 (Figure 2).
Figure 2. Map of Migrant Camps in Adams County, Pennsylvania

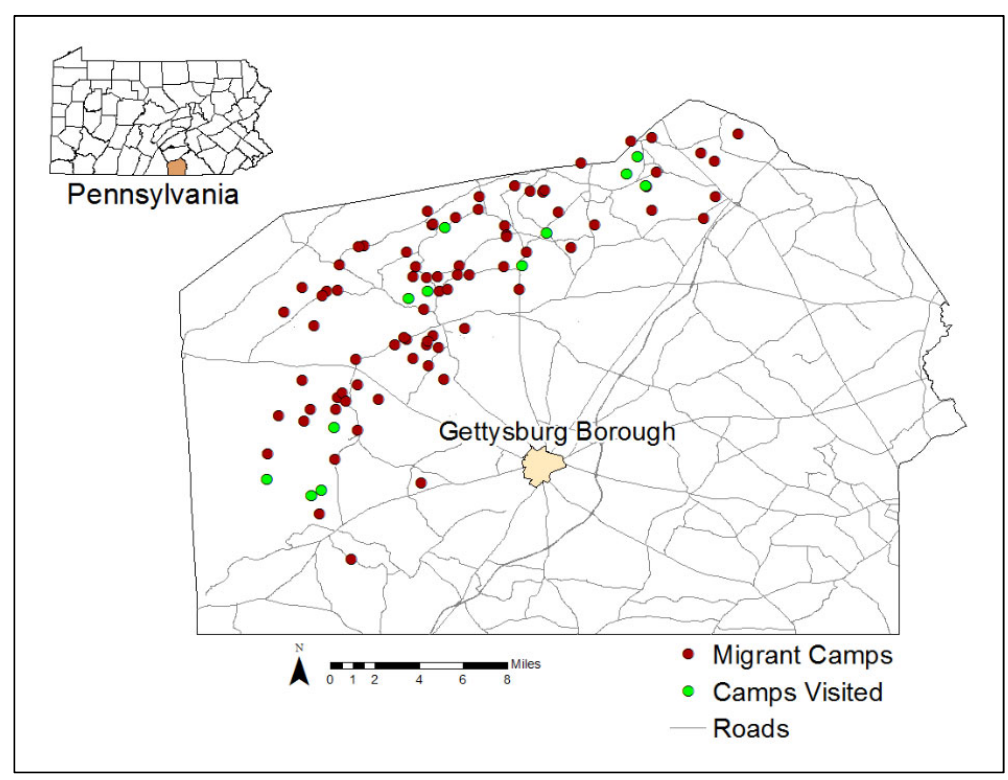


These months are prime apple harvesting season in the nation's sixth-largest apple producing county (U.S. Department of Agriculture, 2012). Interview responses and field notes were compiled in a Microsoft Excel spreadsheet. Additionally, though we did not ask about visa status in the questionnaire, we noted whether respondents voluntarily disclosed their visa status during the interview.

\section{Data Analysis}

Our analysis of survey responses employed both quantitative and qualitative methods. In terms of quantitative methods, descriptive statistics were calculated for the demographic measures. Cross-tabs were used to compare questionnaire responses between the categories shown in Figure 1 (e.g., demographics vs. perceived control, perceived risk vs. risk behavior, etc.). Fischer's Exact test was used to determine the significance of the relationships $(x<0.05)$, while Cramér's V was used to determine the strength of the significant relationships. In addition, Cramér's V was used to identify strongly correlated responses within categories so that they would not be interpreted as separate phenomena. For example, in the case of demographics, age is correlated both with total years working in agriculture and years working in agriculture in the U.S.). We identified redundant relationships through intravariable cross-tab comparisons at $p<0.05$; we then presented the highly correlated variables together as single relationships in the results (Table 2). All quantitative analyses were conducted using SPSS software.

In terms of qualitative methods, we transcribed field notes, carefully noting comments the farmworkers added to their survey responses to showcase specific observations made by the farmworkers in their own words. Similar to grounded theory methodology, which looks for patterns and themes that emerge from within responses, we also examined our data to identify recurrent concerns within the comments and responses of the farmworkers (Bernard, 2011; Scott, 2009). However, as our sample size was small, we did not formally code the responses; instead, our analysis, which involved careful familiarity with notes and cross-checks within the data, sought to highlight additional insights and themes that might have been missed by the statistics.

Table 2. Cramér's V Correlation Tests Conducted to Determine if There is a Correlation Within Demographic, Perceived Risk, and Risk Behavior Variables for Similar Questions/Responses $(n=40)$ No similar perceived control questions were asked.

\begin{tabular}{|c|c|c|}
\hline Variable 1 & Variable 2 & $\begin{array}{l}\text { Cramér's V } \\
\text { significance }\end{array}$ \\
\hline \multicolumn{3}{|c|}{ Demographic Variables } \\
\hline Age & Before US Ag duration & 0.283 \\
\hline Age & US Ag duration & $0.000 *$ \\
\hline Age & Total Ag duration $(<15 / 15+)$ & $0.016 *$ \\
\hline Age & Total Ag duration $(<25 / 25+)$ & $0.002 *$ \\
\hline Before US Ag duration & US Ag duration & 0.433 \\
\hline Before US Ag duration & Total Ag duration $(<15 / 15+)$ & $0.005^{*}$ \\
\hline Before US Ag duration & Total Ag duration $(<25 / 25+)$ & $0.000 *$ \\
\hline US Ag duration & Total Ag duration $(<15 / 15+)$ & $0.011 *$ \\
\hline US Ag duration & Total Ag duration $(<25 / 25+)$ & $0.001 *$ \\
\hline \multicolumn{3}{|c|}{ Perceived Risk Variables } \\
\hline Short exposure & Short impact & $0.000 *$ \\
\hline Short exposure & Short impact fatal & 0.309 \\
\hline Short exposure & Can name short illness & $0.000 *$ \\
\hline Short impact & Short impact fatal & 0.309 \\
\hline Short impact & Can name short illness & $0.001 *$ \\
\hline Short impact fatal & Can name short illness & 0.279 \\
\hline Long exposure & Long impact & $0.000 *$ \\
\hline Long exposure & Long impact fatal & 0.454 \\
\hline Long exposure & Can name long illness & $0.028 *$ \\
\hline Long impact & Long impact fatal & 0.382 \\
\hline Long impact & Can name long illness & $0.049 *$ \\
\hline Long impact fatal & Can name long illness & 0.732 \\
\hline \multicolumn{3}{|c|}{ Risk Behavior Variables } \\
\hline Protective measures & Protect clothing & $0.000 *$ \\
\hline Protective measures & Protect washing & $0.031 *$ \\
\hline Protect clothing & Protect washing & 0.533 \\
\hline
\end{tabular}

* statistically significant relations. 
Table 3. Discrete Demographic Data of Interview Participants $(n=40)$

\begin{tabular}{lcc}
\hline Variable & Frequency & Percentage \\
\hline Sex of respondent & 39 & 97.5 \\
Male & 1 & 2.5 \\
Female & & \\
\hline Highest Level of Education & 3 & 7.5 \\
No formal education & 3 & 7.5 \\
Less than elementary & & \\
school & 7 & 17.5 \\
Less than middle school & 18 & 45 \\
Less than high school & 7 & 17.5 \\
Received high school & & \\
diploma & 1 & 2.5 \\
Some college & 1 & 2.5 \\
Bachelor's degree & & \\
\hline English Proficiency & 19 & 47.5 \\
Not at all & 9 & 22.5 \\
A little & 9 & 22.5 \\
Some & 2 & 5 \\
A lot & 1 & 2.5 \\
Fluent & & \\
\hline
\end{tabular}

\section{Results}

The results-descriptive, cross-tab, and qualitative - reveal a number of important insights. First, descriptive demographics show that the majority of respondents are men, most have not completed high school, and about half are not proficient in English (Table 3). The age of respondents ranged from 20 to 72 years, with a mean age of 38 (Table 4). Second, the cross-tab analysis reveals a number of statistically significant correlations (Figure 3) that were of medium $(\mathrm{V} \approx 0.3)$ to large $(V \approx 0.5)$ magnitude, indicating that the variables were significant and moderately or strongly correlated. The cross-tab results also show that demographics
Table 4. Continuous Demographic Data of Interview Participants $(n=40)$

\begin{tabular}{lccc}
\hline Variable & Minimum & Maximum & Mean \\
\hline Age & 20 & 72 & 38.32 \\
\hline \# of farms & 1 & 8 & 3.525 \\
\# of trainings & 0 & 7 & 2.846 \\
\hline Ag duration in US & 0 & 46 & 13.00 \\
Ag duration before US & 0 & 46 & 14.05 \\
Total ag duration & 0 & 72 & 26.43 \\
\hline
\end{tabular}

Note: Age was used for farmworkers who indicated that they spent their entire life working in agriculture.

influence perceived risk (9 statistically significant relationships), and perceived risk is strongly correlated with perceived control (18 statistically significant relationships). There are fewer correlations between risk behavior and demographics, perceived risk, and perceived control (1,2, and 2, respectively), as only two risk behavior questions were asked. Nonetheless, there are important insights to be gleaned from these few relationships. Third, the qualitative analysis, which consisted of paying attention to statements made by farmworkers, introduced the researchers to certain concerns that had not been captured through the statistics.

Figure 3. Conceptual Model with Results of the Current Study There were 8 total demographic questions, 15 perceived control questions, 12 perceived risk questions, and 2 risk behavior questions in the questionnaire instrument.

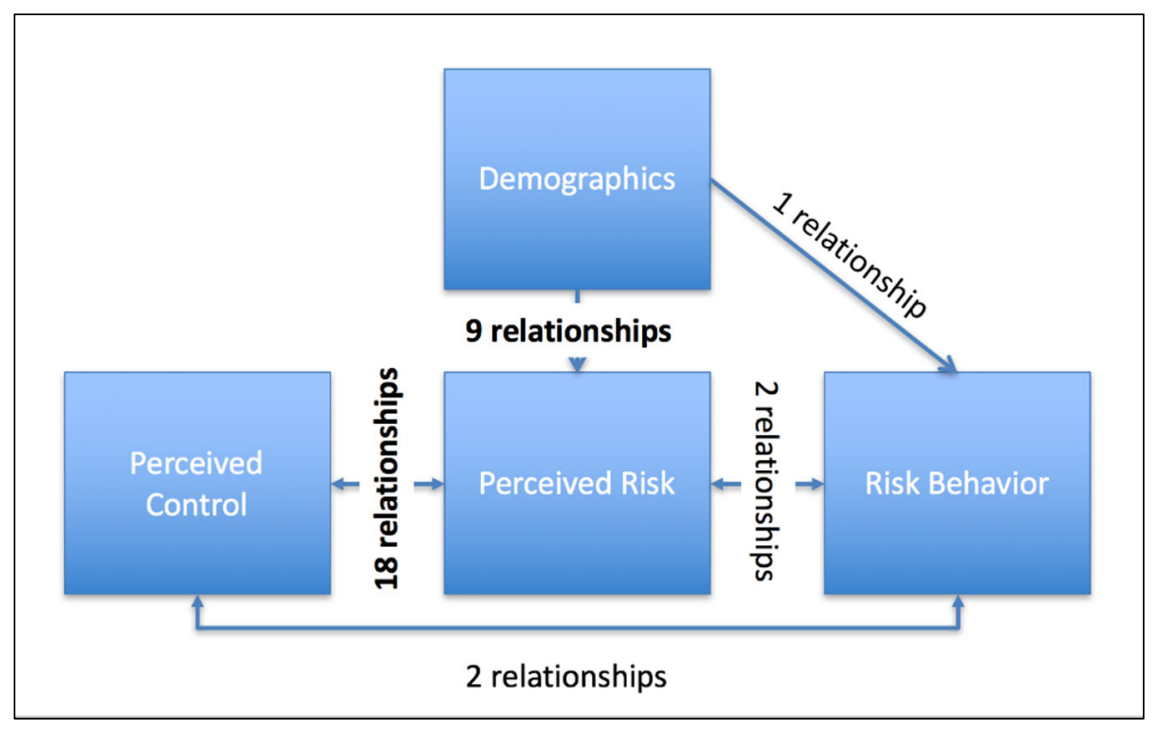


Relationships between Demographics and Control, Perception, Behavior

Demographic factors relate strongly to perceived risk. What is immediately apparent is that farmworkers who might be the most systemically marginalized (those who have to travel to many farms in a year, those who have worked longer in menial jobs, and those who did not disclose their visa status) have a heightened sense of risk perception compared to their respective counterparts (those who work at fewer farms, have worked fewer years, and have disclosed their legal visa status) (Table 5).

Such marginalization might, as Bickerstaff (2004) found in her study on air pollution, cause heightened risk perception and vulnerability. However, our findings are nuanced. For example, farmworkers receive training when they first arrive at a farm; thus, the number of farms they work at correlates with the number of trainings, suggesting that those working at more farms might also be receiving the most education on pesticide risk exposure. Arcury et al.'s (2002) HBM analysis of farmers in North Carolina found that such train- ings increase levels of perceived risk. In general, our findings also indicate, not surprisingly, that those with formal education tend to have a higher risk perception (Table 5), thus reiterating that education - whether in the form of trainings or otherwise-makes farmworkers more aware of pesticide risk hazards.

Interestingly, Arcury et al. (2002) did not find any correlations between demographics and perceived risk; however, our results definitely do find such correlations, aligning more with studies such as that of Damalas and Hashemi (2010) who statistically analyzed the results of 148 interviews with cotton growers in Brazil. Similar to their results, we find that younger farmworkers have higher perceived risk than older farmworkers. Specifically, younger farmworkers ( $<40$ years old) were more likely to report having experienced a pesticide-related illness than older farmworkers ( $\geq 40$ years) $(52.2 \%$ and $11.8 \%$, respectively) $(p=0.017 ; \mathrm{V}=0.419)$. Younger farmworkers also have higher rates of perceiving that short-term pesticide exposure can result in an adverse health impact compared to older farmworkers $(73.7 \%$ and

Table 5. Nature of the Relationship between Several Demographic and Perceived Risk Correlations Conducted through Cross-tab Comparisons

\begin{tabular}{|c|c|c|c|c|}
\hline Demographic Variable & Perceived Risk Variable & $\begin{array}{c}\text { Fisher's } \\
\text { Exact } p \text {-value }\end{array}$ & $\begin{array}{l}\text { Cramér's V } \\
\text { significance }\end{array}$ & Nature of Relationship \\
\hline $\begin{array}{l}\text { \# of farms } \\
(1-4 / 5-8)\end{array}$ & $\begin{array}{l}\text { Experienced pesticide } \\
\text { illness } \\
\text { (yes/no) }\end{array}$ & 0.031 & 0.386 & $\begin{array}{l}\text { Farmworkers who worked at more farms } \\
\text { experienced more pesticide-related } \\
\text { illnesses. }\end{array}$ \\
\hline $\begin{array}{l}\text { \# of farms } \\
(1-4 / 5-8)\end{array}$ & $\begin{array}{l}\text { Short-term pesticide risk } \\
\text { (yes/no) }\end{array}$ & 0.008 & 0.488 & $\begin{array}{l}\text { Farmworkers who worked at more farms } \\
\text { were more likely to acknowledge that } \\
\text { short-term pesticide exposure could } \\
\text { result in an illness. }\end{array}$ \\
\hline $\begin{array}{l}\text { US Ag duration } \\
(<15 / 15+)\end{array}$ & $\begin{array}{l}\text { Experienced pesticide } \\
\text { illness } \\
\text { (yes/no) }\end{array}$ & 0.001 & 0.509 & $\begin{array}{l}\text { Farmworkers who worked longer in U.S. } \\
\text { agriculture had lower rates of reporting } \\
\text { experiencing a pesticide-related illness. }\end{array}$ \\
\hline $\begin{array}{l}\text { Visa } \\
\text { (disclosed work visa } \\
\text { status/did not disclose } \\
\text { work visa status) }\end{array}$ & $\begin{array}{l}\text { Others' health } \\
\text { (cause concern, worry/not } \\
\text { at all, no concern) }\end{array}$ & 0.034 & 0.408 & $\begin{array}{l}\text { Farmworkers who did not disclose their } \\
\text { work visa status are more likely to be } \\
\text { worried for the health of other workers } \\
\text { with regards to exposure. }\end{array}$ \\
\hline $\begin{array}{l}\text { Education (none/formal } \\
\text { education) }\end{array}$ & $\begin{array}{l}\text { Child health } \\
\text { (cause concern, worry/not } \\
\text { at all, no concern) }\end{array}$ & 0.034 & 0.424 & $\begin{array}{l}\text { Farmworkers who have received a } \\
\text { formal education are more likely to be } \\
\text { concerned for the health of children of } \\
\text { farmworkers. }\end{array}$ \\
\hline $\begin{array}{l}\text { Education (none/formal } \\
\text { education) }\end{array}$ & $\begin{array}{l}\text { Can name long-term illness } \\
\text { (yes/no) }\end{array}$ & 0.022 & 0.435 & $\begin{array}{l}\text { Farmworkers who have received a } \\
\text { formal education are more likely to be } \\
\text { able to name an illness associated with } \\
\text { long-term pesticide exposure. }\end{array}$ \\
\hline
\end{tabular}


$33.3 \%$, respectively) ( $p=0.006 ; \mathrm{V}=0.404)$.

The reasons why this is the case are not completely intuitive: younger farmworkers might be better educated on the possible harms associated with pesticide use or be less aware of how to engage in safety behaviors. However, our findings indicate that, as high risk perception is not correlated with factors like education and safety training, younger farmworkers might not be more or less educated than their older counterparts. Instead, like Damalas and Hashemi (2010) indicate, perhaps what we are seeing is that they might be less inclined than their older counterparts to overlook the harms associated with pesticide exposure.

While perceived risk correlates strongly with demographics, there were no statistically significant relationships between demographics and perceived control variables, and there was only one significant relationship between demographics and risk behavior. Farmworkers who did not disclose their working visa status engage in protective safety measures at higher rates than farmworkers who did disclose their working visa status $(93.8 \%$ and $62.5 \%$, respectively) ( $p=0.018 ; \mathrm{V}=0.378$ ) (Appendix B, Table B1). One potential explanation for this relationship is that farmworkers who disclosed their visa statuses might have put more faith in their employer's role in mitigating the risk of pesticide exposure as there is more government regulation and oversight for documented workers than for undocumented workers. This explanation is supported by Arcury, Quandt, Cravey, Elmore, and Russell (2001), who also found that workers with $\mathrm{H}-2 \mathrm{~A}$ work visas were more likely to indicate that there was safety support in their work environments than workers without $\mathrm{H}-2 \mathrm{~A}$ visas.

Finally, our descriptive and qualitative results also reveal how farmworkers often categorize themselves as outside of risk, while they might categorize others at risk. For example, while few farmworkers (4) directly attributed the risks associated with pesticide exposure to those who actually apply the pesticides, many failed to articulate that, as farmworkers, they themselves face risk of exposure. For example, 10 farmworkers did not believe they were at short-term risk, though they agreed such risks do exist; similarly, 17 farm- workers responded that they believe pesticides can put one at long-term risk, but that they themselves are not at risk. Eight farmworkers indicated that, though others were at risk, they personally were not (Questions 27a and b). For example, when asked about his concern for his own health, one farmworker first responded with, "I've never had any problems" (translated). When asked about his concern for the health of his co-workers, he continued, "there's some that get a little sick, they take them to the clinic. We are not all the same. I don't worry about it because the cases are rare" (translated).

In all, our results show the important relationship between demographics and perceived risk, which in turn can help us target specific recommendations for pesticide safety as outlined in the discussion section.

\section{Relationships between Perceived Control and Perceived Risk}

As with numerous other studies (Arcury et al., 2002; Elmore \& Arcury, 2001; Levesque \& Arif, 2014), our results also point to the important ways in which perceived control correlates with perceived risk. Specifically, whether their employers will listen to them, whether they perceive pesticides as safe when used correctly, their own sense of personal responsibility, and the number of trainings farmworkers receive are all perceived control factors that show significant statistical relationships. The first two-whether their employers will listen and whether pesticides are safe when used correctly-indicate inverse relations between perceived control and perceived risk; for example, those who feel less in control over the safety of pesticides or their ability to be heard are those who perceive higher risk (Table 6). Cabrera and Leckie (2009) similarly note how perceived control is inversely related to perceived risk.

Our qualitative analysis shows that farmworkers often elaborated on their negative perception of control by noting that adverse health impacts are also dependent on the strength of the pesticide used or the competency of the pesticide applicators. Further, two workers noted the problems they face when they have to work in adverse weather, a 
Table 6. Nature of Relationship between Several Perceived Control and Perceived Risk Correlations Conducted through Cross-tab Comparisons

\begin{tabular}{|c|c|c|c|c|}
\hline Perceived Control Variable & Perceived Risk Variable & $\begin{array}{c}\text { Fisher's } \\
\text { Exact } p \text {-value }\end{array}$ & $\begin{array}{l}\text { Cramér's } \\
\text { V value }\end{array}$ & Nature of Relationship \\
\hline $\begin{array}{l}\text { Listened by employer } \\
\text { (yes/no) }\end{array}$ & $\begin{array}{l}\text { My health } \\
\text { (cause concern, worry/not } \\
\text { at all, no concern) }\end{array}$ & 0.045 & 0.435 & $\begin{array}{l}\text { Farmworkers who believe they will be } \\
\text { listened by their employer are less likely } \\
\text { to be concerned about the effects of } \\
\text { pesticides on their health. }\end{array}$ \\
\hline $\begin{array}{l}\text { Pesticides safe when } \\
\text { used correctly (yes/no) }\end{array}$ & $\begin{array}{l}\text { Frequency of pesticide } \\
\text { contact } \\
\text { (never, rarely/sometimes, } \\
\text { often, always) }\end{array}$ & 0.019 & 0.461 & $\begin{array}{l}\text { Farmworkers who perceive pesticides } \\
\text { are not safe when used correctly report } \\
\text { more frequent contact with pesticides. }\end{array}$ \\
\hline $\begin{array}{l}\text { Pesticides safe when } \\
\text { used correctly (yes/no) }\end{array}$ & $\begin{array}{l}\text { Experienced pesticide } \\
\text { illness } \\
(y e s / n o)\end{array}$ & 0.005 & 0.528 & $\begin{array}{l}\text { Farmworkers who perceive pesticides } \\
\text { are not safe have higher rates of } \\
\text { reporting having experienced a } \\
\text { pesticide-related illness. }\end{array}$ \\
\hline $\begin{array}{l}\text { Pesticides safe when } \\
\text { used correctly (yes/no) }\end{array}$ & $\begin{array}{l}\text { Seen residue } \\
\text { (yes/no) }\end{array}$ & 0.012 & 0.504 & $\begin{array}{l}\text { Farmworkers who perceive that } \\
\text { pesticides are not safe have higher } \\
\text { rates of reporting having seen pesticide } \\
\text { residue on crops. }\end{array}$ \\
\hline
\end{tabular}

factor they cannot control. For example, rain often causes the pesticide residue to run off the crops and stain workers' clothing. In addition, hot weather heightens the occurrence of headaches and watery eyes. One farmworker noted: "If you're working in the rain and the rain makes the leaves wet, the pesticides run off and stain you...The videos don't tell you how to protect yourself [from this]" (translated).

Conversely, our statistical results show at least seven other inverse relationships where higher perceived control, specifically pertaining to the availability of soap and drinking water and the separation of handwashing water and drinking water, translated to lower perceived risk (Appendix B, Tables B2-B8). These results suggest that farmworkers do appreciate having access to basic safety measures, which ultimately increases their sense of self-efficacy. This finding is also confirmed by Arcury et al. (2002) and Remoundou et al. (2015).

We also see positive relations between perceived control and perceived risk. Those with a greater sense of personal responsibility with regard to the extent of their exposure (a form of selfefficacy) were more knowledgeable about both short-term and long-term pesticide exposure than those who did not identify themselves as being responsible $(69.2 \%$ and $50 \%$, respectively, for short-term exposure and $100 \%$ and $55.6 \%$, respectively, for long-term exposure) (short-term: $p=0.046 ; \mathrm{V}=0.338$ ) (long-term: $p=0.004 ; \mathrm{V}=0.454$ ) (Appendix B, Tables B9 and B10). Further, workers who received more trainings during the year have higher rates of reporting having experienced a pesticide-related illness than farmworkers who have received fewer trainings $(64.3 \%$ for farmworkers who received 4 to 7 trainings and $19.2 \%$ for farmworkers who received 0 to 3 trainings) $(p=0.043 ; \mathrm{V}=0.451)$ (Appendix B, Table B11).

Despite these positive relationships between trainings and perceived control, almost none of the farmworkers referred to the safety training video when answering risk perception or risk behavior questions later in the interview, suggesting that this form of training might not be memorable. In contrast, one farmworker kept referring to a "lady" who spoke with them about pesticide safety following the instructional safety video and was able to refer to her training when answering questions such as Questions 27a and c, My health is burt by pesticides and The health of the children of farmworkers is burt by pesticides, and Question 34, Please list illnesses you believe can result from long-term pesticide exposure. Thus, a human supplement to the instructional safety videos appears to have been more memorable than the video. 
Overall, just as in other studies (Arcury et al., 2002; Elmore \& Arcury, 2001; Levesque \& Arif, 2014), our results highlight that perceived control is statistically significant in understanding perceived risk, and factors such as self-efficacy and cues to action do appear to have an impact on how safe farmworkers feel.

\section{Relationships between Perceived Control and Risk Behavior}

The significant relationships we see between perceived control and risk behavior are illuminating. For example, similar to Arcury et al. (2002) and Remoundou et al. (2015), our findings show that those who are more knowledgeable about the risks of pesticide exposure report higher rates of engaging in protective measures. Comparable to Arcury et al. (2002), whose study highlighted a correlation between perceived risk and the presence of restricted entry signs, we see that the presence of restricted entry signs correlates to an increase in the rate at which farmworkers use clothing as a protective measure against pesticide exposure compared to when there is an absence of restricted entry signs ( $93.1 \%$ and $40.0 \%$, respectively) $(p=0.040$; $\mathrm{V}=0.412$ ) (Appendix B, Table B12).

Interestingly, despite statistically significant correlations that show that the availability of soap leads to a sense of lower perceived risk (Appendix B, Tables B2-B4), its presence did not necessarily translate to an increase in washing, an important safety measure. Instead, counterintuitively, higher rates of soap availability translate to lower rates at which farmworkers engage in washing both themselves and their clothing as a protective measure against pesticide exposure $36.36 \%$ for frequent soap availability and $85.7 \%$ for infrequent soap availability) ( $p=0.033 ; \mathrm{V}=0.377$ ) (Appendix $\mathrm{B}$, Table B13). The study conducted by Snipes et al. (2009) similarly discusses complicated behavior regarding using water as a preventative measure, noting that both a lack of knowledge and certain circumstantial barriers influence why farmworkers might not engage in such safety measures. For example, some farmworkers might delay washing, even if soap is available, due to the belief that one would get sick if they wash while their body temperature is too warm-a belief that several farmworkers (5) in the current study noted.

Our qualitative analysis adds further insight on why farmworkers might not engage in safety behavior, even when they know they might be at risk. For example, one farmworker noted that the safety trainings were not effective; although the safety training videos preached using gloves and masks during work, they were not actually provided with these safety materials. In fact, while many farmworkers (29) indicated that they should cover their bodies and mouths when working (Q37), at least four farmworkers indicated the difficulty of following recommendations. One farmworker commented, "with blueberries, you could cover your mouth to not get dust in; in apples, you can't cover your mouth because it's hard work and you'd get more tired with your mouth covered" (translated). Another farmworker also noted that the "dust" (pesticide residue) affects the eyes, but it is not possible to cover one's eyes while working. This farmworker also experienced a burning sensation in the eyes after working in the fields. Similarly, one of the protective safety measures that many farmworkers mentioned was washing their work clothes. However, when asked about the presence of laundry facilities in the migrant camps (Question 39), only 37.5\% of respondents said that laundry facilities were always provided, and $22.5 \%$ said they were never provided. There also appear to be discrepancies in reported waiting periods after a pesticide has been applied and before a farmworker can reenter that area. Some workers (5) indicated that this period is only $6-48$ hours, while others (8) indicated they had to wait 3 days to 2 weeks. A couple of the farmworkers were illiterate and indicated that they were unable to read the restricted entry signs or written safety materials and/or instructions.

These farmworkers' comments clearly spotlight the barriers to engaging in risk-mitigating behavior when gear and equipment are not always available or when safety instructions are not adequately communicated. As with previous studies (Arcury et al., 2002; Elmore \& Arcury, 2001; Levesque \& Arif, 2014), we see that many farmworkers sense an absence of control over their environments despite 
having awareness of pesticide exposure risk. For example, protective clothing is often hard to use, laundry facilities may not be present, and work must continue no matter what the weather.

\section{Relationships between Perceived Risk and Risk Behavior}

There are two identified relationships between perceived risk and risk behavior, specifically with regard to farmworkers' engagement in protective safety measures such as washing. Perceived risk acts as a modifying factor for risk behavior, as farmworkers who can name an illness associated with long-term pesticide exposure engage in pesticide safety protective measures at higher rates than those who cannot $(96.4 \%$ and $66.7 \%$, respectively) ( $p=0.022 ; \mathrm{V}=0.412$ ) (Appendix $\mathrm{B}$, Table B14). Likewise, farmworkers who can name an illness associated with short-term pesticide exposure engage in washing as a protective safety measure at higher rates than those who cannot (66.7\% and $27.3 \%$, respectively) $(p=0.024$; $\mathrm{V}=0.394)$ (Appendix B, Table B15). These findings correspond to those of Remoundou et al. (2015), who found that risk perceptions play a role in affecting risk behaviors for farm operators, specifically for those whose health has been negatively affected by pesticides. In contrast, Cabrera and Leckie (2009) found that, despite being aware of the potential health impacts of pesticide exposure and having higher levels of risk perception than the general public, farmworkers continued to engage in unnecessary risky behaviors; they reason, as we also suspect through our findings discussed in the previous section, that perceived control can be a confounding factor.

Overall, our cultural risk assessment reveals important insights that confirm observations present in many earlier studies. While trainings and educational materials are valuable to help build awareness of risk perception, systemic factors, such as a lack of control over their circumstances, make it hard for migrant farmworkers to engage in safe behavior. Further, when put in conversation with technical risk assessment, we find additional barriers to ensuring farmworker safety.

\section{Discussion}

As the first study of its kind in Pennsylvania-a mixed method cultural risk assessment in dialogue with a technical risk assessment—our study's results yield many useful insights. These insights are important both because they are the first to focus on migrant farmworkers in Adams Countythe nation's sixth-largest apple-producing regionand because they are applicable to understanding pesticide risk-management practices across the nation. Most notably, the quantitative analyses tease out important relationships between demographics, perceived risk, perceived control, and risk behavior, while our qualitative analysis provides additional information that can help explain reasons underlying some of these relationships. When placed in dialogue with technical risk assessment, they highlight further concerns about government standards for pesticide risk exposure policies, which should not be ignored if we are to safeguard both farmworkers and consumers.

\section{Relationship between Cultural Risk. Assessment and Technical Calculations of Risk}

As described in the introduction, while the EPA has several calculations for determining exposure (Pederson, 1997; U.S. EPA, 1994, 2007; U.S. EPA Office of Pesticide Programs, 2002, 2013; U.S. EPA Office of Superfund Remediation and Technology Innovation, 2004), these are based on a series of generalizable assumptions with many limitations. These limitations become more clear when one considers the findings of our cultural risk assessment. For example, there is no easily available published or reported way to quantify the interaction and cumulative exposure of different pesticides. According to the U.S. Department of Agriculture's National Agricultural Statistics Service, 143 different chemicals (i.e., fungicides, herbicides, insecticides, etc.) were applied to Pennsylvania apple orchards in 2015, with most orchard farmers using between 20 and 50 different products in a given season. While it is not likely that all 143 chemicals were applied to every apple orchard, chemical interactions are likely to occur. Additionally, farmworkers indicated that they travelled to up to eight farms over the course of the year (Table 2). 
According to the cross-tab analysis, farmworkers who worked at more farms had higher perceived risk, specifically with regard to reporting having experienced a pesticide-related illness (Table 4) and knowledge of the impacts of short-term pesticide exposure (Table 4). If farmworkers who are working at more farms during the year and are thus exposed to pesticides for blueberries or oranges in addition to those for apples, we can assume that the resulting higher rates of experiencing a pesticide-related illness could potentially be attributed to the interaction of a diverse variety of chemicals. A recent study regarding the interaction of pesticides in California identified several concerning health effects: decrease in the body's detoxifying ability, altered or damaged DNA, and limited DNA repair and expression enzymes (Zaunbrecher, Hattis, Melnick, Kegley, Malloy, \& Froines, 2016). Equally concerning, the California study only looked at the interaction of three pesticides, nowhere near the 20-50 products that a Pennsylvania orchard farmer may use in one season.

Likewise, there are interactions between pesticides and other external factors, such as heat or moisture, that are not considered in the EPA's calculation of risk (Arcury, Vallejos, Marín, Feldman, Smith, \& Quandt, 2006). As evident through the qualitative analysis, a farmworker noted that rain could cause the pesticide residue to run off the crops, stain worker clothing, and thus increase dermal exposure. Not only is this a limitation that the EPA does not consider, but it also offers evidence of the limitations of a technical risk assessment and highlights the importance of a cultural risk assessment, thus acknowledging the on-the-ground voices of those on the frontlines of our agricultural system.

\section{Limitations}

There are two primary types of limitations to this study: (1) sample size and representativeness of the sample, and (2) survey design and data collection.

\section{Sample size and representativeness of the sample}

The study is limited in size and scope as it has a small sample size (40 farmworkers) and a small representative sample of Adams County (only 13 of the 92 total camps in Adams County were visited). The LIU Migrant Education program noted that there are a variety of workers in different living situations, such as farmworkers who have yearround employment and have permanent residences that are not provided by the employer. Our sample was too small to compare the experiences of farmworkers across camps, and it did not account for different living conditions. For example, some of the visited camps were clean and had laundry facilities, while others were dirty or had broken or flea-ridden furniture. As Arcury et al. (2002) indicate, the variation of living conditions can influence perceived risk and perceived control; thus, additional research incorporating more farmworkers in different living situations will be valuable to assessing perceived control and perceived risk in Pennsylvania farmworker communities.

In addition, there was a marked absence of women and children in the camps, and thus less opportunity to interview women workers and compare risk based on gender. Based on other studies (Anthony, Williams, \& Avery, 2008; Cabrera \& Leckie, 2009; Peres, Rodrigues, da Silva Peixoto Belo, Moreira, \& Claudio, 2013; Remoundou et al., 2015; Snipes et al., 2009) that take gender into consideration, we can hypothesize that including women in future studies will yield important comparative insights. For example, the responses could differ, specifically for question $27 \mathrm{c}$ : The health of the children of farmworkers is burt by pesticides. We observed during data collection that female farmworkers were always accompanied by children in the camps, while male farmworkers were almost never accompanied by children, which leads us to believe that we might see greater concern for children by women farmworkers, as observed in Snipes et al. (2009).

\section{Survey design and data collection}

Similar to many other studies that apply the HBM framework, our use of the model is relatively simplistic, a consequence of the fact that we are operating with a small sample size. Consequently, we are not able to analyze correlations between variables within perceived risk-for example, 
susceptibility and severity, or severity and benefits. Such analyses would be a rich area of potential future research within the context of a larger, more comprehensive survey. Also, like most previous research (Arcury et al., 2002; Quandt et al., 2001; Snipes et al., 2009), this study does not evaluate complex interactions between HBM variables. To do so would require not only a larger survey but a re-working of the HBM model to articulate the ordering of variables (Jones et al., 2015), which is beyond the scope of this study.

Furthermore, because we only have two risk behavior questions, we are not able to draw many conclusions about relationships between perceived risk or perceived control variables and risk behavior variables. To dig deeper into relationships with risk behavior, a future survey could ask open-ended risk behavior questions (e.g., Please list safety measures that you take to reduce any possible harmful effects of pesticide exposure) and then ask when the farmworker engages in risk behaviors. Asking such directed questions would align better with studies such as Arcury et al. (2002) and Snipes et al. (2009), but unfortunately was not feasible in this short survey.

\section{Conclusion and Future Directions for Pesticide Risk Research and Mitigation} Literature on risk assessment, particularly the HBM model, shows that people must first perceive themselves to be at risk in order to take mitigating action, and this is the case in our study. More knowledge of specific pesticide risks by farmworkers does correlate with higher rates of reported preventive risk action. However, our results also indicate that it is not always possible for farmworkers to take preventive action due to the lack of control they have over their environments (e.g., the availability of laundry facilities and protective gear such as gloves and face masks, and the inconvenience of weather). While these findings are consistent with previous studies (Arcury et al., 2002; Cabrera \& Leckie, 2009; Elmore \& Arcury, 2001; Remoundou et al., 2015; Snipes et al., 2009), they provide a clear basis for recommendations in Adams County, Pennsylvania, that can be extended across the nation, especially in terms of what researchers might do to assist in pesticide mitigation strategies.

First, our study's significant correlations between certain demographics (age, education, visa status) and perceived risk provide new insight which is particularly relevant to recommending practices for safer pesticide use. More specifically, while we cannot control the demographics of farmworkers, we can target specific demographics to ensure that all farmworkers feel (and are) protected in their work. This is where researchers can be particularly valuable. For example, we can target older farmworkers differently than younger farmworkers. By facilitating focus groups that tease out the nuances of each demographics work and safety concerns, we can better understand their different risk perceptions. Such additional research is an essential first step to draft safety recommendations that each demographic might employ in their daily lives. Likewise, we can target farmworkers who have not received a formal education and workers who are registered with an H-2A work visa to better understand the reasons for their lower risk perception compared to their counterparts (those with formal education and those without legal status). Second, we must also seriously consider how technical risk assessment is evaluated. It is imperative that there is more clinically based research regarding the effects of chemical interactions, cumulative exposure, and weather on pesticide exposure and absorption. In both recommendations concerning how to increase pesticide knowledge, we encourage the community-based research (CBR) framework, which ensures that stakeholder needs and values are considered. Although we did not employ CBR in its entirety, as stakeholders were not consulted in the creation of the survey instrument, our research was based on the invitation of community partners; we sought to respect and validate the knowledge of stakeholders, and our findings are shared with community members in a variety of ways to help prompt change in factors that determine stakeholder safety. These included two oral presentations-one public presentation attended by the LIU partners and another given to the Adams County Food Policy Council, which includes local partners such as the local Penn State Agricultural unit that liaisons with 
farmers. The results will also be shared freely in written form.

Some recommendations for community members working on the ground include the following possibilities. First, most farmworkers indicated that only one training session was conducted when they first arrived at the Pennsylvania farm. Given that our results correlate greater awareness with more trainings, we recommend having at least one additional training over the course of the harvest season. Second, it is important to ensure that farmworkers are guaranteed a sense of control of their environment-whether this is in in the form of providing bilingual and visual-restricted entry signs for both literate and illiterate farmworkers, or in the form of other preventive actions, such as encouraging washing. For example, bilingual and visual signs for the use of soap in bathrooms coupled with verbal information about the value of washing as a safety precaution might be worthwhile, and the inclusion of laundry facilities by employers is also recommended. Third, our results suggest that bringing in a verbal communicator following the video trainings or switching to inperson trainers altogether may help build the credibility and trustworthiness of the pesticide safety instructions, which in turn can translate to safer behavior. Similarly, we recommend building trust between employer and farmworker by encouraging more dialogue and interaction; as our results indicate, farmworkers who believe their employers will listen to them have a higher sense of control. Overall, we understand that the political realities of agricultural exceptionalism can (and do) hamper the implementation of such recommendations by marginalizing migrant farmworkers in multiple ways. For example, having low-income or undocumented status make certain farmworkers more vulnerable to power dynamics (Gray, 2013; Holmes, 2013; Rodman et al., 2016; Weiler et al., 2016). However, we also recognize that advocating for change based on what farmworkers say is a first step towards ensuring that (1) farmworkers feel that they have control over their health, and (2) that perceived risk aligns with the actual risk they face from pesticide use.

Cultural risk assessment is an important first step in rebalancing inequities of power in our food system. The harms associated with pesticide risk exposure can be successfully mitigated with careful attention to the voices of those on the frontlines of our food system. Not only are more studies needed to fully assess the potential threat to the migrant population and illuminate and mitigate environmental injustices facing this community, but such studies are valuable to frame policies that can more effectively ensure farmworkers' safety.

\section{Acknowledgments}

Special thanks to the U.S. Environmental Protection Agency (EPA) for funding the research. Also, thanks to the Gettysburg College Environmental Studies Department, Gettysburg College Provost's Office, the Center for Public Service, and Lincoln Intermediate Unit (LIU) Migrant Education Program, specifically program recruiters Elvira Rios and Maria Romero. Also, great appreciation to Starla Grove, acting interpreter, and Jocelyn Santianez Regalado, translator for written documents. Finally, we thank Amy Dailey and the anonymous reviewers for their invaluable critical feedback on the paper. 


\section{References}

Allen, P. (2016). Labor in the food system, from farm to table [Editorial]. Journal of Agriculture, Food Systems, and Community Development, 6(2), 1-4. https://doi.org/10.5304/jafscd.2016.062.022

Anthony, M., Williams, J. M., \& Avery, A. M. (2008). Health needs of migrant and seasonal farmworkers. Journal of Community Health Nursing, 25(3), 153-160. https://doi.org/10.1080/07370010802221768

Arcury, T. A., \& Quandt, S. A. (1998). Chronic agricultural chemical exposure among migrant and seasonal farmworkers. Society \& Natural Resources, 11(8), 829-843. https://doi.org/10.1080/08941929809381121

Arcury, T. A., Quandt, S. A., Cravey, A. J., Elmore, R. C., \& Russell, G. B. (2001). Farmworker reports of pesticide safety and sanitation in the work environment. American Journal of Industrial Medicine, 39(5), 487-498. https://doi.org/10.1002/ajim.1042

Arcury, T. A., Quandt, S. A., \& Russell, G. B. (2002). Pesticide safety among farmworkers: Perceived risk and perceived control as factors reflecting environmental justice. Environmental Health Perspectives, 110(Suppl. 2), 233-240. Retrieved from https://www.ncbi.nlm.nih.gov/pmc/articles/PMC1241168/

Arcury, T. A., Vallejos, Q. M., Marín, A. J., Feldman, S. R., Smith, G., \& Quandt, S. A. (2006). Latino farmworker perceptions of the risk factors for occupational skin disease. American Journal of Industrial Medicine, 49(6), 434-442. https://doi.org/10.1002/ajim.20311

Bernard, H. R. (2011). Research methods in anthropology: Qualitative and quantitative approaches (5th ed.). Lanham, Maryland: AltaMira Press.

Bickerstaff, K. (2004). Review article: Risk perception research: Socio-cultural perspectives on the public experience of air pollution. Environment International, 30(6), 827-840. https://doi.org/10.1016/j.envint.2003.12.001

Bookchin, M. (1962). Our synthetic environment. New York: Knopf.

Cabrera, N. L., \& Leckie, J. O. (2009). Pesticide risk communication, risk perception, and self-protective behaviors among farmworkers in California's Salinas Valley. Hispanic Journal of Behavioral Sciences, 31(2), 258-272. https://doi.org/10.1177/0739986309331877

Carson, R. (1962). Silent spring. Boston, Massachusetts: Houghton Mifflin.

Cason, K. L., Snyder, A., \& Jensen, L. (2004). The health and nutrition of Hispanic migrant and seasonal farm workers. Retrieved from the Center for Rural Pennsylvania website: http://www.rural.palegislature.us/migrant_farm_workers.pdf

Ciesielski, S., Loomis, D. P., Mims, S. R., \& Auer, A. (1994). Pesticide exposures, cholinesterase depression, and symptoms among North Carolina migrant farmworkers. American Journal of Public Health, 84(3), 446-451. https://doi.org/10.2105/AJPH.84.3.446

Colt, J. S., Stallones, L., Cameron, L. L., Dosemeci, M., \& Zahm, S. H. (2001). Proportionate mortality among US migrant and seasonal farmworkers in twenty-four states. American Journal of Industrial Medicine, 40(5), 604-611. https://doi.org/10.1002/ajim.1126

Cox, J. R. (2012). Environmental communication and the public sphere (3rd ed.). Thousand Oaks, California: Sage Publications.

Damalas, C. A., \& Hashemi, S. M. (2010). Pesticide risk perception and use of personal protective equipment among young and old cotton growers in northern Greece. Agrociencia, 44(3), 363-371. Retrieved from http://www.scielo.org.mx/scielo.php?pid=S1405-31952010000300010\&script=sci abstract

Elmore, R. C., \& Arcury, T. A. (2001). Pesticide exposure beliefs among Latino farmworkers in North Carolina's Christmas tree industry. American Journal of Industrial Medicine, 40(2), 153-160. https://doi.org/10.1002/ajim.1083

Finucane, M. L., \& Holup, J. L. (2005). Psychosocial and cultural factors affecting the perceived risk of genetically modified food: An overview of the literature. Social Science \& Medicine, 60(7), 1603-1612. https://doi.org/10.1016/j.socscimed.2004.08.007

Gettysburg College, Center for Public Service. (2017). Community-based research. Retrieved from http://www.gettysburg.edu/about/offices/college life/cps/faculty/community-based-research.dot

Gray, M. (2013). Labor and the locavore: The making of a comprehensive food ethic. Berkeley, California: University of California Press.

Hayden, J. (2013). Introduction to health behavior theory (2nd ed.). Burlington, Massachusetts: Jones \& Bartlett Learning. 
Holmes, S. M. (2013). Fresh fruit, broken bodies: Migrant farmworkers in the United States. Berkeley, California: University of California Press.

Jones, C. L., Jensen, J. D., Scherr, C. L., Brown, N. R., Christ, K., \& Weaver, J. (2015). The Health Belief Model as an explanatory framework in communication research: Exploring parallel, serial, and moderated mediation. Health Communication, 30(6), 566-576. https://doi.org/10.1080/10410236.2013.873363

Khan, M. (2010). Using the Health Belief Model to understand pesticide use decisions. Pakistan Development Review, 49 (4, Part II), 941-956. Retrieved from http://www.pide.org.pk/pdf/PDR/2010/Volume4/941-956.pdf

Levesque, D. L., \& Arif, A. A. (2014). Does the perception of psychosocial factors increase the risk of pesticide exposure among seasonal Hispanic farmworkers? International Journal of Occupational \& Environmental Medicine, 5(2), 72-77. Retrieved from http://www.theijoem.com/ijoem/index.php/ijoem/article/view/388

National Center for Farmworker Health. (2012). Farmworker fact sheets. Retrieved from http://www.ncfh.org/fact-sheets-research.html

National Research Council. (1996). Understanding risk: Informing decisions in a democratic society. Washington, DC: National Academies Press. https://doi.org/10.17226/5138

Occupational Safety and Health Act of 1970, 29 U.S.C. \$S651-678 (2004).

Pedersen, T. L. (1997). Risk characterization. Retrieved February 23, 2017, from the University of California, Davis website: http://extoxnet.orst.edu/faqs/risk/char.htm

Peres, F., Rodrigues, K. M., da Silva Peixoto Belo, M. S., Moreira, J. C., \& Claudio, L. (2013). Design of risk communication strategies based on risk perception among farmers exposed to pesticides in Rio de Janeiro state, Brazil. American Journal of Industrial Medicine, 56(1), 77-89. https://doi.org/10.1002/ajim.22147

Quandt, S. A., Arcury, T. A., \& Pell, A. I. (2001). Something for everyone? A community and academic partnership to address farmworker pesticide exposure in North Carolina. Environmental Health Perspectives, 109(Suppl. 3), $435-441$. Retrieved from https://www.ncbi.nlm.nih.gov/pubmed/11427393

Remoundou, K., Brennan, M., Sacchettini, G., Panzone, L., Butler-Ellis, M. C., Capri, E.,...Frewer, L. J. (2015). Perceptions of pesticides exposure risks by operators, workers, residents and bystanders in Greece, Italy and the UK. Science of the Total Environment, 505, 1082-1092. https://doi.org/10.1016/j.scitotenv.2014.10.099

Renn, O. (1992). Concepts of risk: A classification. In S. Krimsky \& D. Golding (Eds.), Social theories of risk (pp. 53-79). Westport, Connecticut: Praeger Publishers.

Rodman, S. O., Barry, C. L., Clayton, M. K., Frattaroli, S., Neff, R. A., \& Rutkow, L. (2016). Agricultural exceptionalism at the state level: Characterization of wage and hour laws for U.S. farmworkers. Journal of Agriculture, Food Systems, and Community Development, 6(2), 89-110. https://doi.org/10.5304/jafscd.2016.062.013

Sakala, C. (1987, Autumn). Migrant and seasonal farmworkers in the United States: A review of health hazards, status, and policy. The International Migration Review, 21(3), 659-687. https://doi.org/10.2307/2546616

Scott, H. (2009, November 1). What is grounded theory? Retrieved June 20, 2017, from the Grounded Solutions Ltd. website: http://www.groundedtheoryonline.com/what-is-grounded-theory/

Snipes, S. A., Thompson, B., O’Connor, K., Shell-Duncan, B., King, D., Herrera, A. P., \& Navarro, B. (2009). "Pesticides protect the fruit, but not the people": Using community-based ethnography to understand farmworker pesticide-exposure risks. American Journal of Public Health, 99(Suppl. 3), S616-S621. https://doi.org/10.2105/AJPH.2008.148973

Southern Poverty Law Center. (2013, February 18). Close to slavery: Guestworker programs in the United States. Retrieved from https://www.splcenter.org/20130218/close-slavery-guestworker-programs-united-states

U.S. Department of Agriculture [USDA], Census of Agriculture. (2012). 2012 Census of Agriculture county profile: Adams County, Pennsylvania. Retrieved from https://www.agcensus.usda.gov/Publications/2012/Online_Resources/ County Profiles/Pennsylvania/cp42001.pdf

USDA, National Agricultural Statistics Service. (2015). Quick stats [Table]. Retrieved from https:/ quickstats.nass.usda.gov/\#6A5B1F6C-A7D2-3C68-B47D-4DF4C2B7EF0D 
U.S. Environmental Protection Agency [EPA]. (1994). Methods for derivation of inhalation reference concentrations (RfCs) and applications of inhalation dosimetry (No. 600/8-90/066F). Retrieved from https://cfpub.epa.gov/ncea/risk/recordisplay.cfm?deid $=71993$

U.S. EPA. (2005). Human Health Risk. Assessment Protocol (HHRAP) for hazardous waste combustion facilities (No. EPA530-D05-006). Retrieved from https://archive.epa.gov/epawaste/hazard/tsd/td/web/pdf/05hhrapcover.pdf

U.S. EPA. (2007). Dermal exposure assessment: $A$ summary of EP A approaches (No. 600/R-07/040F). Retrieved from https://cfpub.epa.gov/ncea/risk/recordisplay.cfm?deid=183584

U.S. EPA, Office of Pesticide Programs. (2002). Guidance on cumulative risk assessment of pesticide chemicals that have a common mechanism of toxicity. Retrieved from https://www.epa.gov/sites/production/files/201507/documents/guidance on common mechanism.pdf

U.S. EPA, Office of Pesticide Programs. (2013). Science advisory council for exposure (ExpoS AC) policy 3 (Policy No. 3). Retrieved from https://www.epa.gov/sites/production/files/2015-08/documents/exposac-policy-3march2013.pdf

U.S. EPA, Office of Superfund Remediation and Technology Innovation. (2004). Risk assessment guidance for Superfund volume I: Human health evaluation manual (part E, supplemental guidance for dermal risk assessment). Retrieved from https://www.epa.gov/sites/production/files/2015-09/documents/part e final revision 10-03-07.pdf

Weiler, A. M., Levkoe, C. Z., \& Young, C. (2016). Cultivating equitable ground: Community-based participatory research to connect food movements with migrant farmworkers. Journal of Agriculture, Food Systems, and Community Development, 6(2), 73-87. https://doi.org/10.5304/jafscd.2016.062.012

Wilk, V. A. (1986). The occupational health of migrant and seasonal farmworkers in the United States (2nd ed.). Washington, DC: Farmworker Justice Fund, Inc.

Worker Protection Standard, 40 C.F.R. $\$ \$ 170.1-170.609$ (2017).

Zaunbrecher, V., Hattis, D., Melnick, R., Kegley, S., Malloy, T., \& Froines, J. (2016). Exposure and interaction: The potential bealth impacts of using multiple pesticides. Retrieved from the Sustainable Technology \& Policy Program website: http://www.stpp.ucla.edu/sites/default/files/Exposure and Interaction 2016 Web 0.pdf 


\section{Appendix A. Survey Instrument, Reorganized by Risk Assessment Categories: Demographics, Perceived Control, Perceived Risk, Risk Behavior, and Technical Risk}

Question abbreviations used in

cross-tab tables

Demographics Questions

1. What is your age?

2. What is your gender?

Age

3. What is the highest level of education you have achieved? What

Gender

country did you receive this education?

4. To what extent can you speak/understand/read English?

Education

5. Where does your family originate?

6. How long have you been working in agriculture in the U.S.?

English

Origin

7. How long have you been working in agriculture before you were in the U.S.?

8. Where have you worked in the past year?

Ag duration US

Ag duration before US (Total Ag duration)

Perceived Control Questions

9. What was your housing situation(s)?

10. Do you like working in agriculture?

11. If you were not working in agriculture, what is something else you would like to be doing with your time?

13. Do you get paid by the hour? Or by quantity?

20. In the past year, how many times were you trained or provided with materials regarding pesticide safety?

21. Are you trained at every farm you work at?

23. Are you told when pesticides are applied?

24. Are restricted entry interval signs posted? Are they in Spanish and/or English?

25. Does your employer speak (or have someone who can speak) Spanish?

26. Do you believe you would be listened to by your employer, the government, or an independent agency if you had concerns that your (or your family's) health was at risk because of your work in agriculture? Why/Why not?

35. Do you believe you have control over avoiding any possible effects of pesticides that can be harmful to your health?

36. Do you agree with the following statement, "Pesticides are not harmful if used correctly"?

39. For the following questions, please indicate the frequency of which these activities occur:

a. Soap is available for you in the fields

b. Toilets are available for you in the fields

c. Drinking water is available to you in the fields

d. There are separate drinking and handwashing water

e. You are required to eat in the fields

f. You have access to laundry facilities in the camps

g. You are provided with showers and adequate plumbing

h. Your employer has told you to dress/work safely

i. Your co-workers talk about safety

j. Your co-workers take safety precautions

40. In the past year, how many times have you seen a physician or went to a healthcare provider?

43. Whose job do you think it is to primarily ensure that pesticides do not cause harm?
\# of farms

Housing

Like Ag

Alt. work

Pay type

\# of trainings

Trainings everywhere

Told application

Restricted signs/Sign lang.

Employer Spanish

Listened by Employer

Control

Pesticides safe

Available soap

Available toilets

Available drinking

Separate water

Eat in fields

Available laundry

Available showers

Employer talk safety

Co-workers talk safety

Co-workers take safety

Physician visits

Responsibility (Self is responsible,

Employer is responsible, Gov. is responsible) 


\section{Perceived Risk Questions}

19. How often do you have direct contact with pesticides?

22. Do you believe these trainings/educational materials are effective in promoting your safety and health?

27. Please indicate your answers to the following regarding your perception of health impacts:

a. My health is hurt by pesticides

b. The health of other farmworkers is hurt by pesticides

c. The health of the children of farmworkers is hurt by pesticides

d. The health of unborn children of farmworkers is hurt by pesticides

e. The ability of farmworkers to have children is hurt by pesticides

28. Do you believe your health is hurt by other work-related conditions? How have you seen health effects related to that?

29. Do you believe short-term pesticide exposure can result in illnesses (direct or indirect exposure after several weeks)?

30. What short-term health impact does exposure have?

31. Please list illnesses you believe can result from short-term pesticide exposure.

32. Do you believe long-term pesticide exposure can result in illnesses (direct or indirect exposure over several years)?

33. What health impact does long-term exposure have?

34. Please list illnesses you believe can result from long-term pesticide exposure.

38. Do you think the following activities reduce your pesticide exposure (yes/no/maybe)

a. washing hands: before eating, before drinking, before smoking, before using the toilet, after using the toilet

b. washing work clothes: after 1 day in the field, separately from non-work clothes

c. wearing: gloves, boots, coveralls/overalls, chemical resistant clothing, bandana/head covering

d. changing clothes: before leaving work, upon immediate return from work

e. showering: before leaving work, upon immediate return from work

41. Have you experienced health outcomes/illnesses that you believe are directly related to pesticide exposure?

\section{Risk Behavior Questions}

37. Please list safety measures that you take to reduce any possible harmful effects of pesticide exposure.

42. Would you stop working in agriculture if your health was being compromised? At what point?

Technical Risk Questions

12. How many hours do you work each day on average? How many days a week?

14. What crop(s) did you work with in the past year (and where)?

15. What were you primarily doing with the crops (pruning, harvesting)?

16. Do you know if pesticides were applied to the crops? How do you know?
Freq. pest contact

Effective trainings

My health

Others' health

Child health

Unborn health

Ability health

Other work conditions

Short exposure

Short pest. Impact/Short pest. Impact fatal Can name short illness

Long exposure

Long pest. impact

Can name long illness

Wash hands

Wash clothes

Wear

Change clothes

Shower

Pesticide illness
Protective measures (Protective clothing, Protective washing, Protective avoid areas) When stop
Hours/days

Which crops

Crop activity

Told application 
Journal of Agriculture, Food Systems, and Community Development ISSN: 2152-0801 online https://www.foodsystemsjournal.org

17. Do you know any of the pesticide names?

18. Do you know how the pesticides were generally applied (ground, aerial, sprinkler irrigation)?

Note: "Visa" (worker has a government-contracted work visa) and "Seen residue" (worker has indicated the presence of pesticide residue on crop) are abbreviated responses from farmworkers that were not explicitly asked in the survey instrument but were still used when conducting statistical tests.
Pest. Names

Application method 


\section{Appendix B. Results: Cross-tab Comparisons}

\section{Demographics (variable 1) as Modifying Factor for Risk Behavior (variable 2)}

Table B1. Cross-tab comparison of whether farmworkers have disclosed that they have an $\mathrm{H}-2 \mathrm{~A}$ work visa (based on whether they return to Mexico during the year [Question 8]) and whether they engage in a protective safety measure (Question 37). $n=40$; Fisher's Exact $p=0.046$; Cramér's V=0.378.

\begin{tabular}{lccc} 
& \multicolumn{3}{c}{ Protective measures } \\
\cline { 2 - 4 } \multicolumn{1}{l}{ Visa } & Something & Nothing & Total \\
\hline Disclosed work visa status & 5 & 3 & 8 \\
Did not disclose work visa status & 30 & 2 & 32 \\
\hline Total & 35 & 5 & 40
\end{tabular}

Relations between Perceived Control (variable 1) and Perceived Risk (variable 2)

Table B2. Cross-tab comparison of the frequency of reported soap availability in the fields (Question 39a) and whether they reported having experienced a pesticide-related illness (Question 41). $n=40$; Fisher's Exact $p=0.039$; Cramér's V=0.352.

\begin{tabular}{lrrc}
\multicolumn{1}{c}{ Soap available } & \multicolumn{3}{c}{ Pesticide illness } \\
\cline { 2 - 4 } \multicolumn{1}{c}{ Yes } & No & Total \\
\hline Sometimes-rarely-never & 5 & 2 & 7 \\
Often-always & 9 & 24 & 33 \\
\hline Total & 14 & 26 & 40
\end{tabular}

Table B3. Cross-tab comparison of the frequency of reported soap availability in the fields (Question 39a) and whether farmworkers reported having seen pesticide residue (not asked in question). $n=40$; Fisher's Exact $p=0.006$; Cramér's $\mathrm{V}=0.494$

\begin{tabular}{lrrc}
\multicolumn{3}{c}{ Soap available } & \multicolumn{3}{c}{ Seen residue } \\
\cline { 2 - 4 } \multicolumn{1}{l}{} & Yes & No & Total \\
\hline Sometimes-rarely-never & 5 & 2 & 7 \\
Often-always & 5 & 28 & 33 \\
\hline Total & 10 & 30 & 40
\end{tabular}

Table B4. Cross-tab comparison of the frequency of reported soap availability in the fields (Question 39a) and whether farmworkers can name an illness associated with short-term pesticide exposure (Question 31). $n=40$; Fisher's Exact $\mathrm{p}=0.033$; Cramér's $\mathrm{V}=0.377$.

\begin{tabular}{lrrc} 
& \multicolumn{3}{c}{ Can name short illness } \\
\cline { 2 - 4 } \multicolumn{1}{c}{ Soap available } & Yes & No & Total \\
\hline Sometimes-rarely-never & 6 & 1 & 7 \\
Often-always & 12 & 21 & 33 \\
\hline Total & 18 & 22 & 40
\end{tabular}


Table B5. Cross-tab comparison of the frequency of reported drinking water availability in the fields (Question 39c) and how frequently farmworkers reported having contact with pesticides (Question 19). $n=39$; Fisher's Exact $p=0.000$; Cramér's $\mathrm{V}=0.680$.

\begin{tabular}{lccc} 
Drinking water available & \multicolumn{3}{c}{ Freq. pest. contact } \\
\cline { 2 - 4 } & Rarely-never & $\begin{array}{c}\text { Sometimes-often- } \\
\text { always }\end{array}$ & Total \\
\hline Sometimes-rarely-never & 0 & 6 & 6 \\
Often-always & 28 & 5 & 33 \\
\hline Total & 28 & 11 & 39
\end{tabular}

Table B6. Cross-tab comparison of the frequency of reported drinking water availability in the fields (Question 39c) and whether farmworkers reported having seen pesticide residue (not asked in question). $n=40$; Fisher's Exact $p=0.002$; Cramér's V=0.566.

\begin{tabular}{lccc} 
Drinking water available & \multicolumn{3}{c}{ Seen residue } \\
\cline { 2 - 4 } \multicolumn{1}{l}{} & Yes & No & Total \\
\hline Sometimes-rarely-never & 5 & 1 & 6 \\
Often-always & 5 & 29 & 34 \\
\hline Total & 10 & 30 & 40
\end{tabular}

Table B7. Cross-tab comparison of the frequency of reported drinking water availability in the fields (Question 39c) and whether farmworkers reported having experienced a pesticide-related illness (Question 41). $n=40$; Fisher's Exact $p=0.001$; Cramér's V=0.572.

\begin{tabular}{lrrr} 
Drinking water available & \multicolumn{3}{c}{ Pesticide illness } \\
\cline { 2 - 4 } \multicolumn{1}{c}{} & Yes & No & Total \\
\hline Sometimes-rarely-never & 6 & 0 & 6 \\
Often-always & 8 & 26 & 34 \\
\hline Total & 14 & 26 & 40
\end{tabular}

Table B8. Cross-tab comparison of the frequency of separate handwashing and drinking water availability (Question 39d) and whether farmworkers perceive the safety trainings as effective in promoting their health (Question 22). $n=37$; Fisher's Exact $p=0.027$; Cramér's V=1.000.

Separate water

\begin{tabular}{lrcc}
\cline { 2 - 4 } & Yes & No & Total \\
\hline Never & 0 & 1 & 1 \\
Often-always & 36 & 0 & 36 \\
\hline Total & 36 & 1 & $\mathbf{3 7}$
\end{tabular}


Table B9. Cross-tab comparison of whether farmworkers perceive themselves as responsible for protecting themselves against pesticide exposure (Question 43) and whether they can name an illness associated with short-term pesticide exposure (Question 31). $n=40$; Fisher's Exact $p=0.046$; Cramér's V=0.338.

\begin{tabular}{lrrc} 
Self is responsible & \multicolumn{3}{c}{ Can name short illness } \\
\cline { 2 - 4 } & Yes & No & Total \\
\hline Yes & 9 & 4 & 13 \\
No & 9 & 18 & 27 \\
\hline Total & 18 & 22 & 40
\end{tabular}

Table B10. Cross-tab comparison of whether farmworkers perceive themselves as responsible for protecting themselves against pesticide exposure (Question 43) and whether they can name an illness associated with long-term pesticide exposure (Question 34). $n=40$; Fisher's Exact $p=0.004$; Cramér's V=0.454.

\begin{tabular}{lccc} 
& \multicolumn{3}{c}{ Can name long illness } \\
\cline { 2 - 4 } \multicolumn{1}{l}{ Self responsible } & Yes & No & Total \\
\hline Yes & 13 & 0 & 13 \\
No & 15 & 12 & 27 \\
\hline Total & 28 & 12 & 40
\end{tabular}

Table B11. Cross-tab comparison of number of trainings farmworkers reported having over the course of the year (Question 20) and whether they reported having experienced a pesticide-related illness (Question 41). $n=40$; Fisher's Exact $p=0.043$; Cramér's V=0.451.

\begin{tabular}{lrrc} 
& \multicolumn{3}{c}{ Pesticide illness } \\
\cline { 2 - 4 } & Yes & No & Total \\
\hline $0-3$ & 5 & 21 & 26 \\
$4-7$ & 9 & 5 & 14 \\
\hline Total & 14 & 26 & 40
\end{tabular}

\section{Relation between Perceived Control (variable 1) and Risk Behavior (variable 2)}

Table B12. Cross-tab comparison of whether restricted entry signs are posted (Question 24) and whether they use clothing as a protective safety measure (Question 37). $n=33$; Fisher's Exact $p=0.040$; Cramér's V=0.412.

\begin{tabular}{lrcc} 
& \multicolumn{3}{c}{ Protective clothing } \\
\cline { 2 - 4 } \multicolumn{1}{l}{ Restrict entry signs } & Yes & No & Total \\
\hline Yes & 27 & 2 & 29 \\
No & 2 & 3 & 5 \\
\hline Total & 29 & 5 & 34
\end{tabular}


Table B13. Cross-tab comparison of the frequency of reported soap availability in the fields (Question 39a) and whether they use washing as a protective safety measure (Question 37). $n=40$; Fisher's Exact $p=0.033$; Cramér's V=0.377.

\begin{tabular}{lrrc} 
& \multicolumn{3}{c}{ Protective washing } \\
\cline { 2 - 4 } Soap available & Yes & No & Total \\
\hline Sometimes-rarely-never & 6 & 1 & 7 \\
Often-always & 12 & 21 & 33 \\
\hline Total & 18 & 22 & 40
\end{tabular}

\section{Relation between Perceived Risk (variable 1) and Risk Behavior (variable 2)}

Table B14. Cross-tab comparison of whether farmworkers can name an illness associated with long-term pesticide exposure (Question 34) and whether they engage in some form of protective safety measure (Question 37). $n=40$; Fisher's Exact $p=0.022$; Cramér's $V=0.412$.

\begin{tabular}{lccc} 
Can name long illness & \multicolumn{3}{c}{ Protective measures } \\
\cline { 2 - 4 } \multicolumn{1}{l}{} & Something & Nothing & Total \\
\hline Yes & 27 & 1 & 28 \\
No & 8 & 4 & 12 \\
\hline Total & 35 & 5 & 40
\end{tabular}

Table B15. Cross-tab comparison of whether farmworkers can name an illness associated with short-term pesticide exposure (Question 31) and whether they use washing as a protective safety measure (Question 37). $n=40$; Fisher's Exact $\mathrm{p}=0.024$; Cramér's V=0.394.

\begin{tabular}{lrrc} 
Can name short illness & \multicolumn{3}{c}{ Protective washing } \\
\cline { 2 - 4 } \multicolumn{1}{l|}{} & Yes & No & Total \\
\hline Yes & 12 & 6 & 18 \\
No & 6 & 16 & 22 \\
\hline Total & 18 & 22 & 40
\end{tabular}

